\title{
Article \\ Design of a Dual-Purpose Patch Antenna for Magnetic Resonance Imaging and Induced RF Heating for Small Animal Hyperthermia
}

\author{
Donghyuk Kim ${ }^{1}$, Daniel Hernandez ${ }^{2}$ 递 and Kyoung-Nam Kim ${ }^{1,2, *}$ \\ 1 Department of Health Sciences and Technology, GAIHST, Gachon University, Incheon 21999, Korea; \\ qnrrmrtjdeye@gmail.com \\ 2 Department of Biomedical Engineering, Medical Campus, Gachon University, Incheon 21936, Korea; \\ theasdwmove@gmail.com \\ * Correspondence: kyoungnam.kim@gachon.ac.kr; Tel.: +82-32-820-4263; Fax: +82-32-460-8230
}

Citation: Kim, D.; Hernandez, D.; Kim, K.-N. Design of a Dual-Purpose Patch Antenna for Magnetic Resonance Imaging and Induced RF Heating for Small Animal Hyperthermia. Appl. Sci. 2021, 11, 7290. https://doi.org/10.3390/ app11167290

Received: 2 June 2021

Accepted: 6 August 2021

Published: 8 August 2021

Publisher's Note: MDPI stays neutral with regard to jurisdictional claims in published maps and institutional affiliations.

Copyright: (c) 2021 by the authors. Licensee MDPI, Basel, Switzerland. This article is an open access article distributed under the terms and conditions of the Creative Commons Attribution (CC BY) license (https:/ / creativecommons.org/licenses/by/ $4.0 /)$.

\begin{abstract}
The popularity of patch antennas in magnetic resonance imaging (MRI) has reduced because of the large size required for patch antennae to resonate. Since the size of the patch antenna is associated with the wavelength and the wavelengths that are used in MRI are substantially large, large antennas are used. Methods of reducing patch antenna sizes have been proposed; however, these methods reduce the penetration depth and uniformity. In this study, we reduced the area of the patch antenna by $30 \%$ by folding the ground and patch planes in a zigzag pattern. The patch antenna produced two main resonant modes. The first mode produced a uniform magnetic field that was used for MRI. The second mode produced a strong and focused electric ( $|\mathrm{E}|$ )-field, which was used for radiofrequency (RF) heating. Furthermore, we explored the use of a combination of two patch antennas aligned along the $z$-axis to provide a circular uniform magnetic flux density $\left(\left|\mathrm{B}_{1}\right|\right)$ field at $300 \mathrm{MHz}$, which corresponds to the Larmor frequency in the 7T MRI system. In addition, the patch antenna configuration will be used for RF heating hyperthermia operating at $1.06 \mathrm{GHz}$. The target object was a small rat with insertion of colon cancer. Using the proposed configuration, we achieved $\left|\mathrm{B}_{1}\right|$-field uniformity with a standard deviation of $3 \%$ and a temperature increment of $1^{\circ} \mathrm{C}$ in the mimic cancer tissue.
\end{abstract}

Keywords: MRI; patch antenna RF heating hyperthermia; full body MRI

\section{Introduction}

Preclinical animal models play an important role in understanding of human disease. It is applied to a variety of research, ranging from diagnosis methods and treatments for diseases. Especially Magnetic resonance imaging (MRI) is a medical imaging method that allows the acquisition of anatomical images from small animals [1-3]. MR images can be employed to diagnose cancer and tumor tissues [4-7]. In addition, MRI is the predominant method for performing non-invasive temperature measurement during hyperthermia treatments [8-12]. Scientists study cancer properties and treatments using ultra-high field MRI, and preclinical studies in controlled environments are usually performed with small animals such as rats and mice $[12,13]$. In order to provide a stable hyperthermia protocol in clinical practice, it is necessary to accurately measure changes in energy transfer parameters (applied power level, heating duration) in small animal experiments, for which we integrate a system of heating and temperature monitoring. Most heating experiments of small animal integrated with MRI have been implemented in clinical MR scanners. Since the animal MRI system has a smaller bore size than the clinical MRI system, there is a technical limitation in integrating it with a heating device in the limited space [14].

The results of previous works $[15,16]$ indicate the usefulness of heat treatment induced into tumor cells of small animals through a heating system. In previous studies, focused 
ultrasound, radiofrequency (RF) and microwave (MW) were used as heating systems that can be combined with MRI systems [17-21]. Specifically, RF or MW energy is applied to the target area in the form of an electric ( $|\mathrm{E}|$ )-field through various types of antennas such as slots, dipoles, bow ties, etc. [18-22] to induce a temperature rise of $\sim 43{ }^{\circ} \mathrm{C}$ or higher in the target tissue. In combination with radiotherapy and/or chemotherapy the hyperthermia treatments with an increased exposure time has shown to produce constant cell death rate [22]. In ref. [19] it is shown that the use of a Yagi-Uda antenna for hyperthermia applications operating at $433 \mathrm{MHz}$, it exhibited low coupling with the imaging RF coils operating at $64 \mathrm{MHz}$. This is an important aspect when designing an RF transmitter for hyperthermia. Similar to Yagi-Uda antennas, Patch antennas are a type of electromagnetic field generator that consist of a dielectric material placed between the ground and patch plane. At frequencies above $400 \mathrm{Mhz}$, there are also studies for the purpose of thermal treatment of patch antennas [23-25]. Even though these studies were combined with an MRI system, MR images acquisition and heating were operated separately. MR image acquisition and heating using the SAR value for a bow-tie antenna that can operate in two ways has been proposed [21].

In this study, we present a dual-purpose patch antenna that can be used for MRI imaging and RF heating hyperthermia. To do that, we need to solve a few problems. The first problem is that at $300 \mathrm{MHz}$, the 7T MRI operating frequency, the size of the antenna is too large to be applied to small animals. The second issue is the $\left|\mathrm{B}_{1}\right|$-field profile according to the orientation of the antenna, as the $\left|\mathrm{B}_{1}\right|$-field consists of the $\mathrm{B}_{\mathrm{x}}$ and $\mathrm{B}_{\mathrm{y}}$ components of the magnetic field. For MRI, RF coils that can transmit and receive a uniform and strong $\left|\mathrm{B}_{1}\right|$-field are preferred. If the antenna is placed on the $z-y$ plane, as is common for any RF coil, the $\left|\mathrm{B}_{1}\right|$-profile has a low intensity because the major component of the magnetic field in this orientation is the $\mathrm{z}$ component of the magnetic field $\mathrm{B}_{\mathrm{z}}$, which is not part of the $\left|\mathrm{B}_{1}\right|$-field. To solve these problems, we first reduced the size of the patch antenna such that it is suitable for applications with small animals, such as a rat; second, we aimed to combine the reduced patch antenna in a configuration to improve the imaging $\left|\mathrm{B}_{1}\right|$-field and simultaneously produce a strong focused electric field that can be used for RF heating. The proposed antenna configuration has the advantage that it has the potential to be used in small animal MRI bore and in human size scanner; this is possible since the size of the antenna is small, and it can perform imaging and RF heating with the same device. We evaluated the temperature increase using the proposed antenna.

\section{Methods}

\subsection{Patch Antenna without Size Reduction}

Patch antennas consist of a patch and a ground plane made of a conductor material, in between the patch and the ground plane a dielectric material is placed. The patch plane is typically rectangular, and the resonant mode of the patch antenna depends on the wavelength. The width and length of the patch plane and the height of the dielectric material for a specific frequency are calculated using the formula for patch antenna found in [23]. For the case of a patch antenna operating at a frequency of $300 \mathrm{MHz}$, as used in a 7T MRI system, and if the dielectric material has a permittivity $\varepsilon_{\mathrm{r}}=6.45$ and height of $30 \mathrm{~mm}$, the computed values for the width would be $258.9 \mathrm{~mm}$ and length $209.9 \mathrm{~mm}$; such an antenna is show in Figure 1a. The resonant modes after matching to $50 \mathrm{Ohms}$ of the patch antenna are shown in Figure 1b. The first resonant frequency is at $300 \mathrm{MHz}$, and the second is located at $430 \mathrm{MHz}$. The magnetic | $\mathrm{B}_{1} \mid$-field pattern of this antenna at $300 \mathrm{MHz}$ in the $y-z$ plane is show in Figure 1c, and the corresponding electric field at $429 \mathrm{MHz}$ is shown in Figure 1d. 

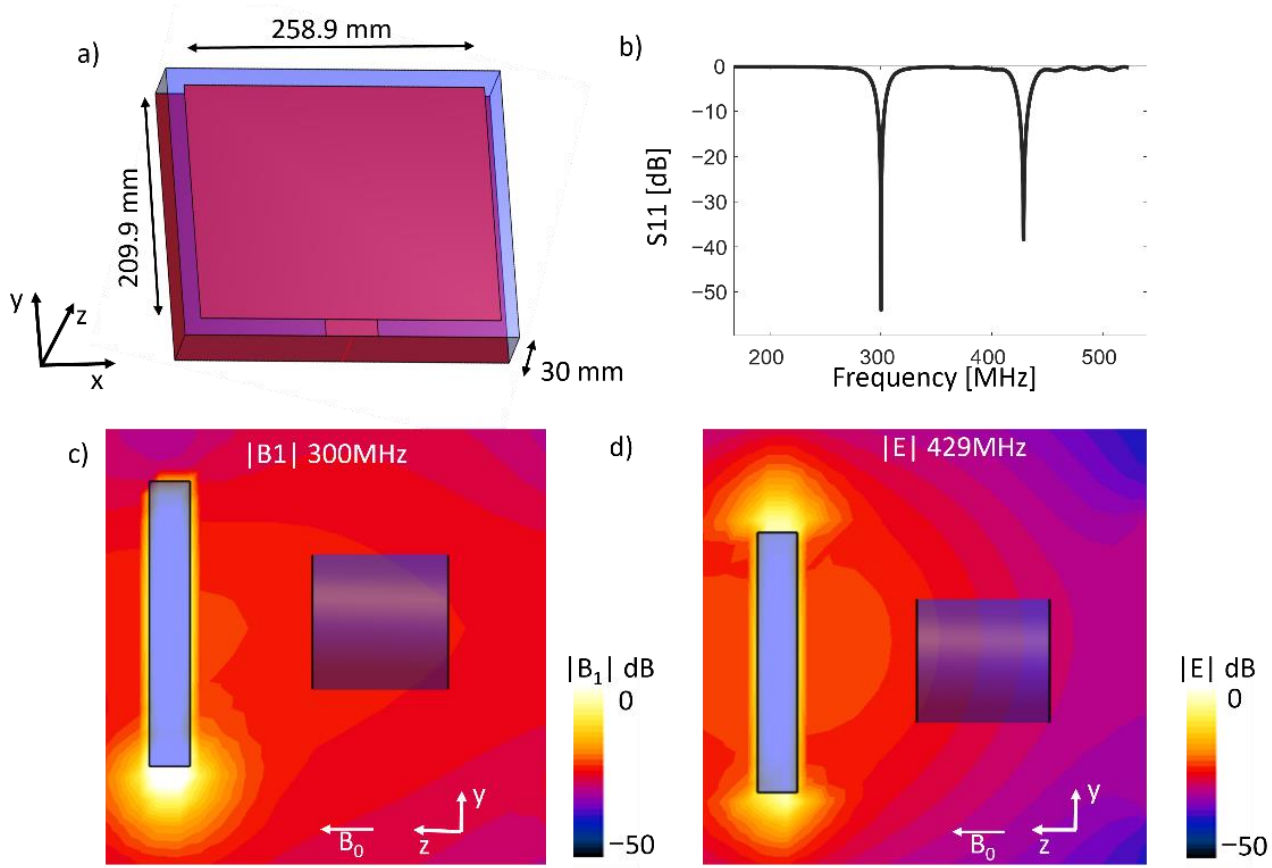

Figure 1. Design of (a) a patch antenna without size reduction, (b) $S_{11}$ parameters of the antenna showing dual frequency, (c) the $\left|\mathrm{B}_{1}\right|$-field of the antenna at $300 \mathrm{MHz}$ and (d) the $|\mathrm{E}|$-field at $429 \mathrm{MHz}$.

This dual resonance frequency can be exploited such that the first resonant frequency can be used for transmitting and receiving in the MRI procedure and the second frequency can be employed for hyperthermia applications.

\subsection{Patch Antenna with Size Reduction}

Size reduction methods for patch antennas have been actively researched [26-30]. One of the most common methods to reduce the size of the antennas is to use meander patterns [30]. As described in the introduction, the resonant modes of the patch antenna are related to the frequency and size of the antenna. Thus, we propose reducing the size of the antenna using the effective length and width of the antenna [24,25,31], by folding the antenna in a zigzag manner. The width of the antenna is reduced by meandering the ground plane in a number of steps $(n)$ in the horizontal direction so that the plane consists of two horizontal and two vertical lines. The height of each step is $h x$, and the length of each step is $l x$ such that the effective length can be described by the following equation:

$$
W=2 n(h x+l x)
$$

Figure 2 shows the application of this equation and the meandering method. By choosing $n=5$ and $h x=10 \mathrm{~mm}, l x$ becomes $18.76 \mathrm{~mm}$, which makes the total width of the antenna $187.6 \mathrm{~mm}$. A similar equation and method can be used to reduce the length of the antenna, and in this work, we applied meandering on the patch plane in the vertical direction. A non-uniform meander patter will allow us to design the antenna to have a straight patch plane at the center, as to uninterrupted conductor area closer to the phantom or the rat so that the field can be of higher intensity. To reduce the length of the antenna, we opted to have a non-uniform meander pattern on the patch plane. 
a)

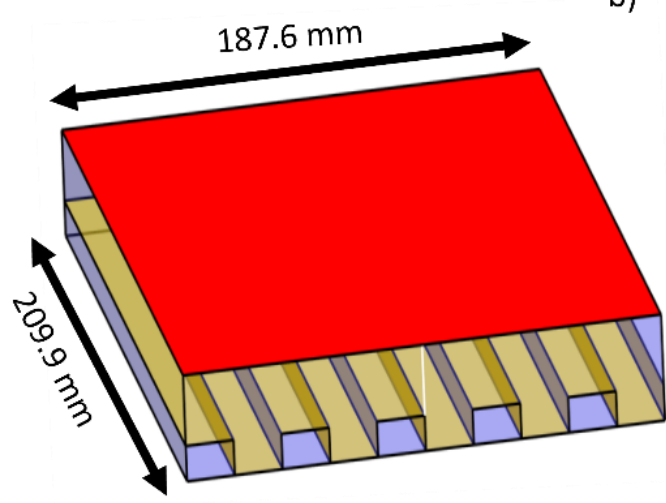

b)

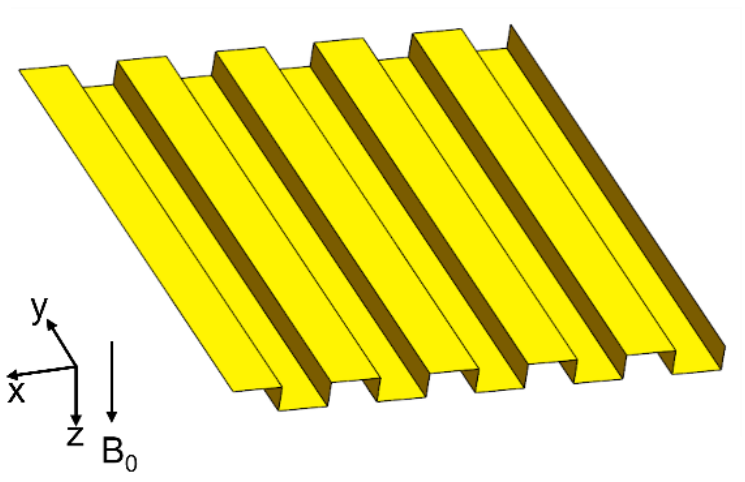

Ix $18.76 \mathrm{~mm}$

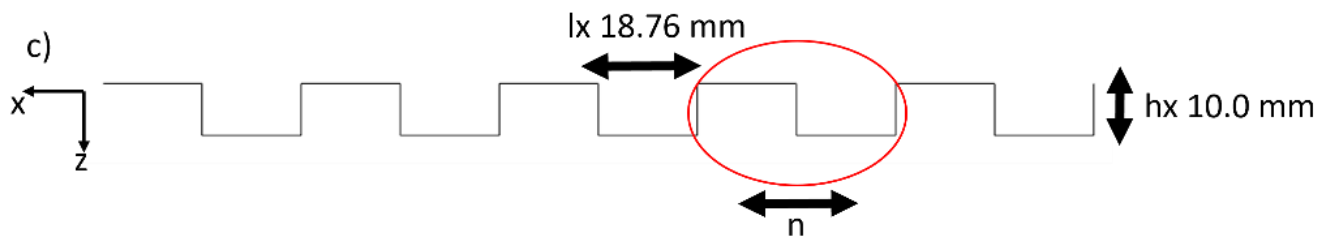

Figure 2. The design of the patch antenna (a) with reduction in the horizontal direction, (b) the ground plate showing the meandering pattern and (c) the diagram of the meandering pattern and dimensions.

We further reduced the size of the antenna by applying a number of steps $n=10$ in the horizontal direction and $n=3$ in the vertical direction, for the ground and patch plane, respectively. The size of the horizontal step $h x$ was $10 \mathrm{~mm}$ and $l x$ was $4.5 \mathrm{~mm}$, the vertical hy was set to $15 \mathrm{~mm}$ and $l y$ was 32.5 , and $20 \mathrm{~mm}$ for the small steps and $50 \mathrm{~mm}$ for the larger plane in the middle of the antenna. Figure 3 shows the final geometry. The height, width and length of the dielectric material were 30, 99 and $150 \mathrm{~mm}$, respectively. In Figure $3 \mathrm{~b}$ the ground plane is shown with the corresponding meandering pattern, and Figure $3 \mathrm{c}$ for the top plane of the patch.

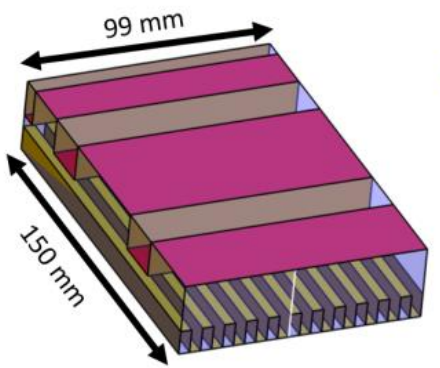

a)

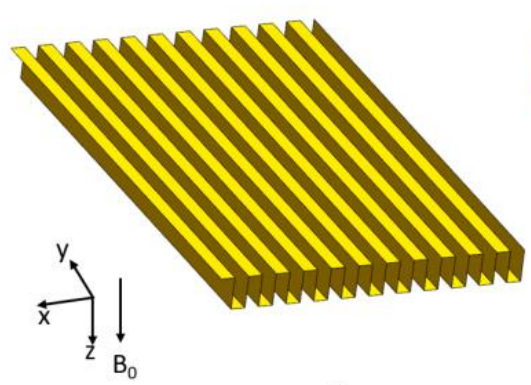

b)

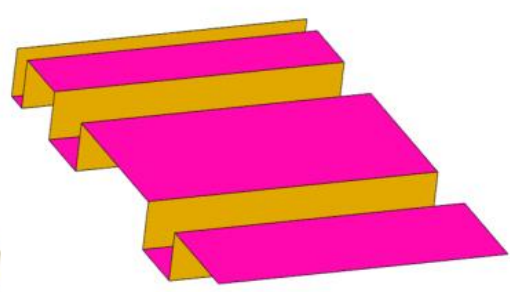

c)

Figure 3. (a) The reduced patch antenna in the vertical and horizontal directions, (b) the ground plane meandering pattern and (c) the patch (top) plane meandering pattern.

\subsection{Simulation Setup}

We performed EM simulations using the commercial software Sim4Life (Zurich med tech, https: / /zmt.swiss/sim4life/, accessed on 10 March 2021). Sim4Life is an FDTD based software to solve Maxwell's equations and for electromagnetic analysis, it also provides computation of the temperature based on the RF excitation from an antenna. Two types of EM simulations were performed, one for acquiring a $\left|\mathrm{B}_{1}\right|$-field operating at $300 \mathrm{MHz}$ for MRI applications and the other to produce an electric field at $1.06 \mathrm{GHz}$ which was consequently used to compute the temperature rise in the target cancer-mimicking tissue. We used the antennas shown in Figure 4, and the dielectric material selected was a Rogers 
RT duroid 6006 with a conductivity of $0.0015 \mathrm{~S} / \mathrm{m}$ and permittivity of 6.45 at $300 \mathrm{MHz}$ and $1.06 \mathrm{GHz}$. We excited the antennas with a Gaussian pulse with a central frequency of $300 \mathrm{MHz}$ and $600 \mathrm{MHz}$ bandwidth, and the second simulation using a central frequency of $1.06 \mathrm{GHz}$ with a bandwidth of $2 \mathrm{GHz}$.

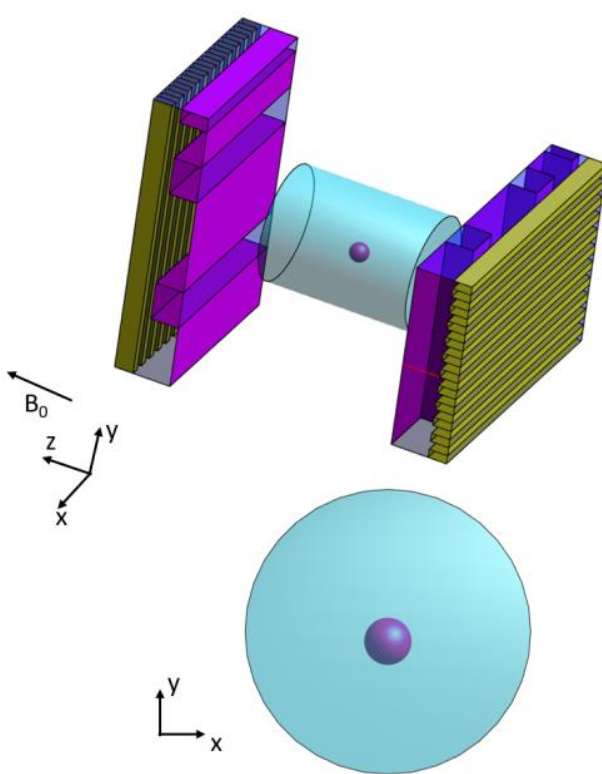

a)

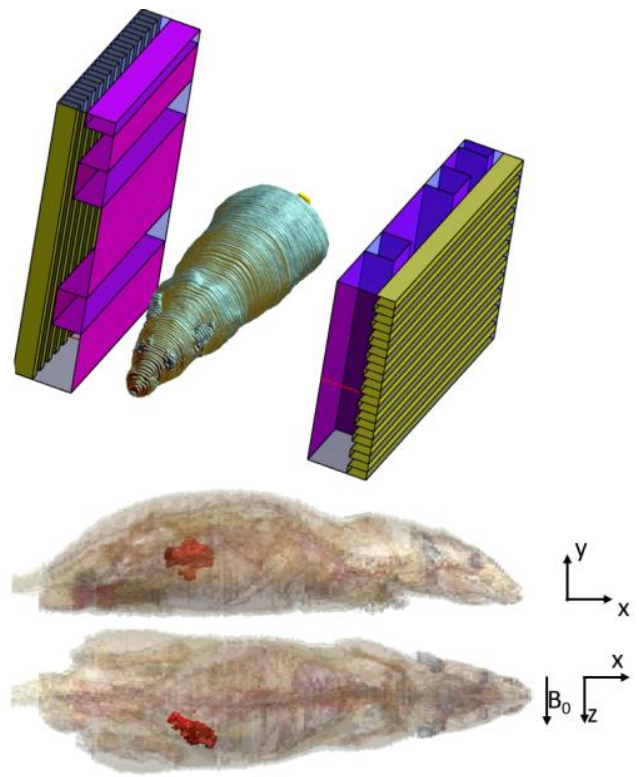

b)

Figure 4. The arrangement of the double patch antenna (a) for a cylindrical phantom and (b) a rat model, showing the cancer-mimicking tissue.

To produce a uniform magnetic field, we used two patch antennas positioned along the $z$-axis and exited with a phase difference such that the field between them was highly uniform. For this purpose, we placed a second patch antenna and rotated it by $90^{\circ}$ phase with around the $z$-axis. By having two antennas in the $x-y$ plane and applying a $90^{\circ}$ phase difference, a uniform circular polarized magnetic field can be produced.

Using this configuration, a circular magnetic field was produced in the middle of the antennas. With this configuration, a focused I E I-field can be achieved. Figure 4 shows the arrangement of the double patch antennas. In Figure 4a the cylindrical phantom is shown with the patch antennas. Figure $4 \mathrm{~b}$ shows the rat model with the orientation between the patch antennas, and also indicating in highlighted red color the cancer-mimicking voxels.

A cylindrical phantom with a radius of $30 \mathrm{~mm}$ and a length of $80 \mathrm{~mm}$ was positioned along the $z$-axis to demonstrate the capabilities of the patch antenna arrangement, with electrical properties equivalent to the tissues of the large intestine with an electrical conductivity and permittivity of $0.77 \mathrm{~S} / \mathrm{m}$ and 58.20 , respectively, at $300 \mathrm{MHz}$. The spherical cancer-mimicking tissue is a sphere of $5 \mathrm{~mm}$ radius that was placed in the middle of the cylinder phantom. The cancer-mimicking tissue had a conductivity of $1.05 \mathrm{~S} / \mathrm{m}$ and permittivity of 62.85 , these values were based on previously reported results on electrical properties measurements of rodent's cancers [32]. For RF heating, the electrical properties were updated using the database and model provided by the Sim4life. The values set at $1.06 \mathrm{GHz}$ for the cylindrical phantom were $1.0 \mathrm{~S} / \mathrm{m}$ and 54.7 for electrical conductivity and permittivity, respectively. To update the values of the spherical cancer-mimicking tissue we used the ref. [32] for which the conductivity was set to $1.2 \mathrm{~S} / \mathrm{m}$ and the permittivity to 59.6. Furthermore, we used the computed $|\mathrm{E}|$-field to estimate the temperature change inside the phantom. The changes in the induced temperature $(T)$ of a tissue over time $(t)$ are described by the Pennes bioheat equation (PBE) [21,33], which is given by

$$
\rho C_{p} \frac{\partial T}{\partial t}=\nabla \cdot(k \nabla T)+Q_{m}+S A R+\rho_{b} C_{p, b} \rho \omega_{b}\left(T_{a}-T\right)
$$


where $k$ is the thermal conductivity in $\mathrm{W} /(\mathrm{m} \cdot \mathrm{K}), \mathrm{T}$ is the tissue temperature in ${ }^{\circ} \mathrm{C}, Q_{m}$ is the specific metabolic heat generation rate, SAR is the specific absorption rate, $C_{p}$ is the heat capacity of the tissues in $\mathrm{J} /(\mathrm{kg} \cdot \mathrm{K})$ and $\omega_{\mathrm{b}}$ is the perfusion rate given in $1 / \mathrm{s} . \rho$ is the tissue density $\left(\mathrm{kg} / \mathrm{m}^{3}\right) ; \rho_{b}, C_{p, b}$ and $T_{a}$ are the density, specific heat capacity and the temperature of the blood, respectively. All these values are specific to each tissue. The specific absorption rate SAR is related to the energy in the form of the IE I-field deposited into the tissue and is calculated by the electric field:

$$
S A R=\frac{\sigma \cdot|E|^{2}}{\rho}
$$

where $\sigma$ is the electrical conductivity $(\mathrm{S} / \mathrm{m})$, and $\rho$ is the tissue density $\left(\mathrm{kg} / \mathrm{m}^{3}\right)$. As the equations indicate, the temperature depends on the electric field and the conductivity of the tissue. Therefore, a strong and focused IEI-field is desired. For this simulation, we used the Pennes algorithm for $200 \mathrm{~s}$, and the thermal parameters for the tissues were assigned automatically using the Sim4Life software database. A power of $5 \mathrm{~W}$ was applied enough to increase the temperature by $1{ }^{\circ} \mathrm{C}$.

Furthermore, we applied the patch antenna configuration to a rat of $196 \mathrm{~mm} \times 50 \mathrm{~mm}$ $\times 55 \mathrm{~mm}$ with a mass of $198 \mathrm{~g}$. Rat 3D models were provided by the animal model from the library of Vizoo (ITIS foundation, Zurich, https: / /itis.swiss/, accessed on 18 February 201), by using the "Big Male Rat". This model consisted of 52 tissues with the respective electrical properties. The boundary condition at the rat were set with the background of Neumann boundary condition with a Heat Flux of $0 \mathrm{~W} / \mathrm{m}^{2}$, and the initial condition for the air was set to $25^{\circ} \mathrm{C}$. The use of the Neumann boundary condition fixes the heat flux at the interface; the sign of this value determines whether the flux flows into or out of the material. This boundary condition used with a heat flux of $0 \mathrm{~W} / \mathrm{m}^{2}$ results in thermal insulation of the boundary, removing the need for water bolus. The skin had a heat transfer rate of $7969.16 \mathrm{~W} / \mathrm{m}^{3} / \mathrm{K}$. In the rat model, we also included a cancer-mimicking tissue, which was the target tissue for the RF heating system, the cancer tissue had an electrical conductivity and permittivity of $1.05 \mathrm{~S} / \mathrm{m}$ and 62.85 , respectively, at $300 \mathrm{MHz}$ and electrical conductivity and permittivity of $1.2 \mathrm{~S} / \mathrm{m}$ and 59.6 at $1.06 \mathrm{GHz}$, the conductivity and permittivity values of the cancer tissue was selected based on the measurements in ref. [32]. The cancer tissue was modeled by using part of the large intestine, and the final model was carried out by intersecting a sphere and the large intestine, separating the normal tissue and the cancer tissue by changing the electrical properties as described previously. We used the same simulation setup as the phantom simulations for both the EM and temperature computations, except for using a power of $10 \mathrm{~W}$.

\section{Results}

By using the method of folding the ground and patch plane, it was possible to reduce the size of the antenna to a size of 99 by $150 \mathrm{~mm}$. Figure 5 shows the $S_{11}$ parameters of the proposed antenna configuration; despite the size reduction, the two-resonance mode was still present. 
a)

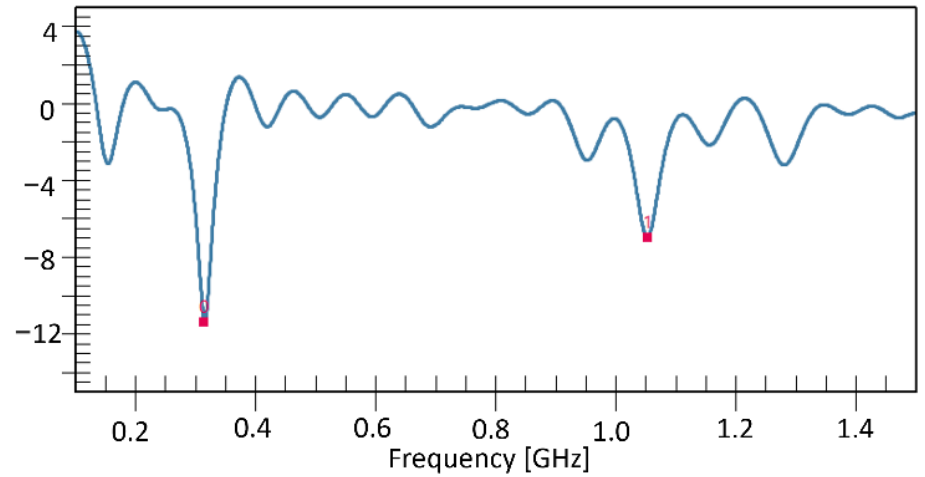

b)

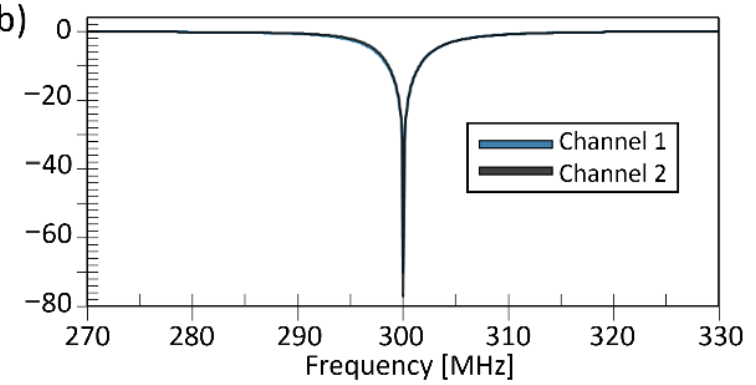

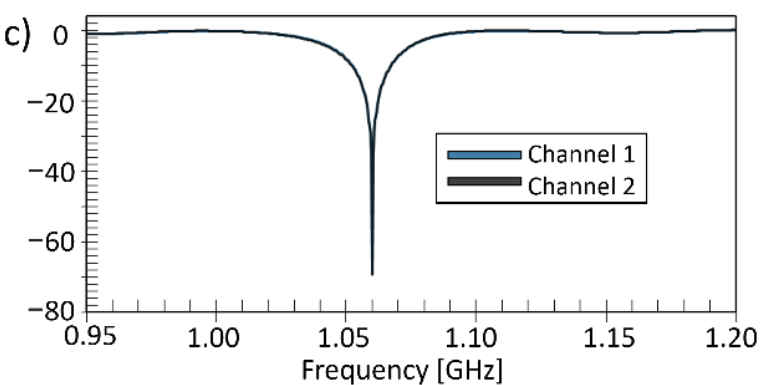

Figure 5. The $\mathrm{S}_{11}$ parameters of the proposed patch antenna, (a) with two main resonance frequencies of $300 \mathrm{MHz}$ and 1.06 GHz. performed $50 \mathrm{ohm}$ matched (b) at $300 \mathrm{MHz}$ and (c) at $1.06 \mathrm{GHz}$ each of two proposed patch antennas.

We performed $50 \mathrm{ohms}$ matching of the two channels to apply for the MRI application and RF heating application. Separate matching circuits base on LC networks were applied to the antennas. Figure $5 \mathrm{~b}, \mathrm{c}$ show $\mathrm{S} 11$ parameter of the proposed antenna was obtained below $-60 \mathrm{~dB}$ each mode.

The resonant frequencies have a current distribution such that a uniform $\left|\mathrm{B}_{1}\right|$ field can be produced, the magnitude and phase of the current density J for the $300 \mathrm{MHz}$ and $1.06 \mathrm{GHz}$ is show in Figure 6, a uniform current density can be seen at the middle patch plane, thus the reason for selecting a non-uniform meander pattern.
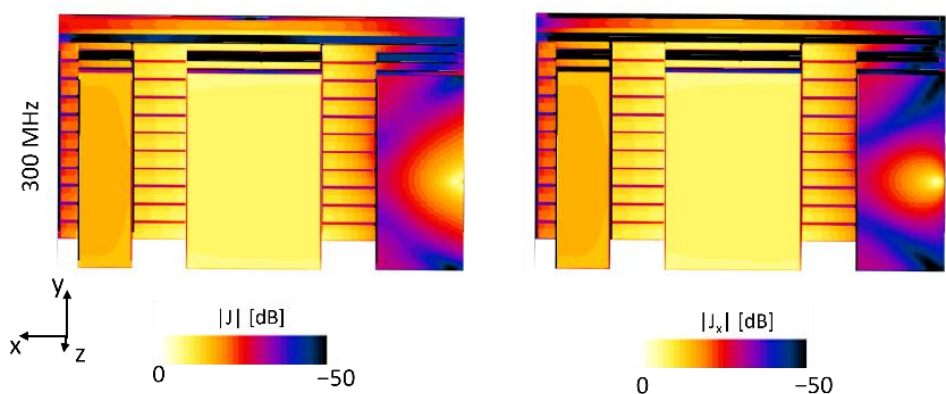

$\left|J_{x}\right|[d B]$
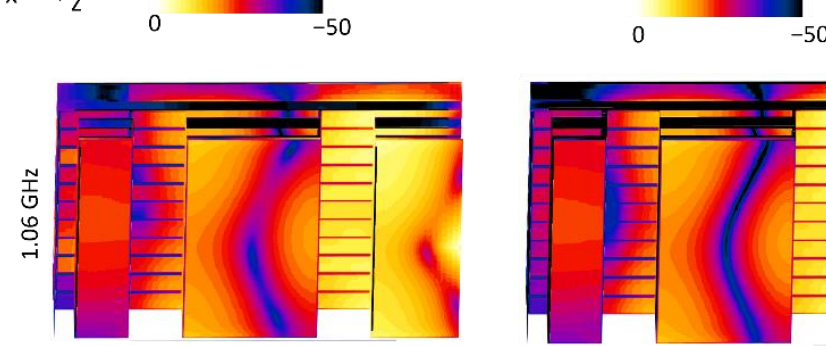

a)
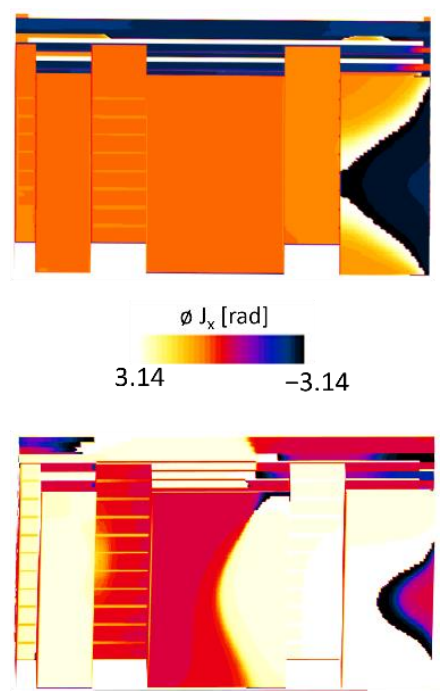

c)

Figure 6. The current density distribution J of the proposed patch antenna. Showing in the top of the figure the $300 \mathrm{MHz}$ and bottom the $1.06 \mathrm{GHz}$, for (a) the vector field of the current density, (b) the x component of current density, $\mathrm{J}_{\mathrm{x}}$ and (c) the phase of $\mathrm{J}_{\mathrm{x}}$. 


\subsection{Phantom Simulations}

The $\left|\mathrm{B}_{1}\right|$-field in the phantom at $300 \mathrm{MHz}$ and the $|\mathrm{E}|$-field at $1.06 \mathrm{GHz}$ are shown in Figure 7, while Figure 7c shows the temperature maps and in Figure 7c the temperature difference between the normal tissue and the target cancer tissue.

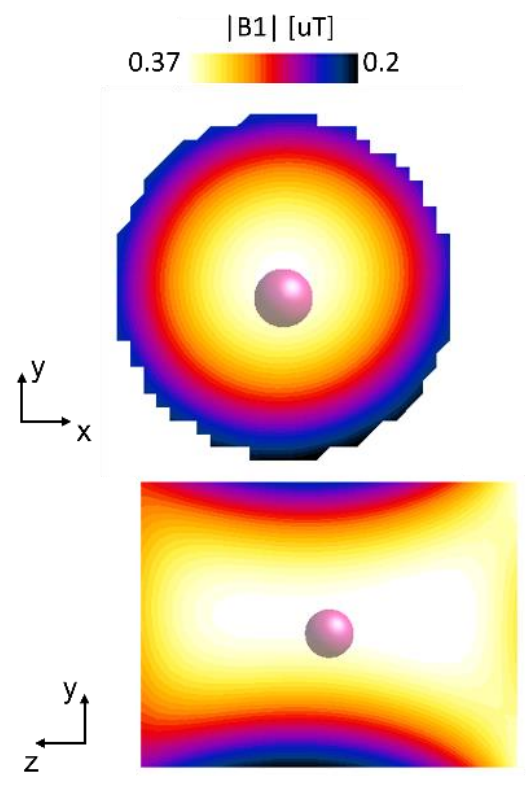

a)

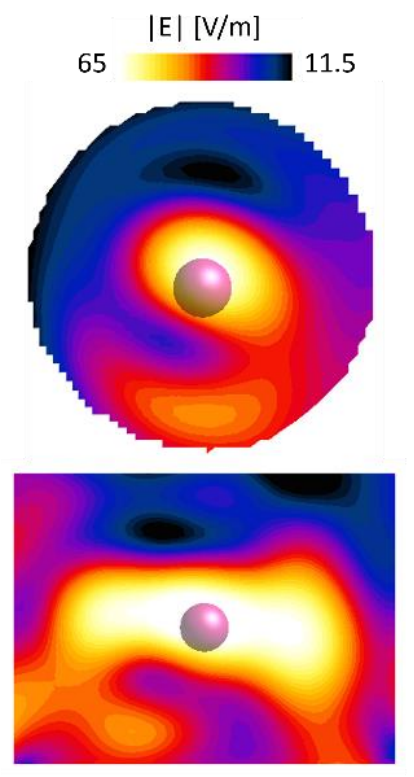

b)
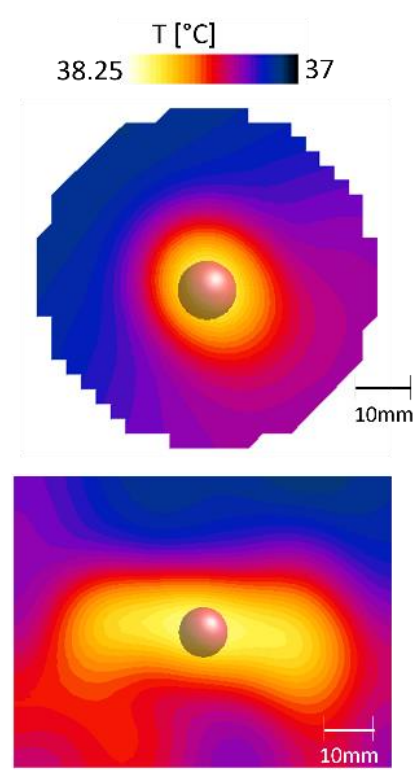

c)

Figure 7. The computed (a) | B |-field, (b) |E |-field and (c) temperature map for the cylindrical phantom.

The $\left|\mathrm{B}_{1}\right|$-field mean value for the whole phantom at the center slice was $0.3 \mu \mathrm{T}$, with a standard deviation of $0.048 \mu \mathrm{T}$, showing a highly uniform field. The E field had a peak value of $71 \mathrm{~V} / \mathrm{m}$ at the location of the cancer tissue, whereas the temperature after $200 \mathrm{~s}$ at the cancer tissue was $38.3^{\circ} \mathrm{C}$. The mean value of the background tissue was maintained at $37.34{ }^{\circ} \mathrm{C}$, whereas the mean value of the cancer-mimicking tissue was $38.1{ }^{\circ} \mathrm{C}$.

\subsection{Rat Simulations}

Figure 8 shows the | B1 |-field, | E |-field and temperature map under the same conditions $\left(\mathrm{S}_{11}\right)$ as the phantom simulation.

The proposed patch antenna configuration can produce a uniform $\left|\mathrm{B}_{1}\right|$-field in the target area; furthermore, it shows that it can also be used for RF heating applications. The $\left|\mathrm{B}_{1}\right|$-field in the target area had a mean value of $0.27 \mu \mathrm{T}$ and a standard deviation of $0.0082 \mu \mathrm{T}$. The electric field had a maximum value of $400 \mathrm{~V} / \mathrm{m}$, and the temperature had an average value of $37.8^{\circ} \mathrm{C}$ and maximum value of $38.2^{\circ} \mathrm{C}$ in the cancer tissue after $200 \mathrm{~s}$. For the background tissues the average temperature was $37.35^{\circ} \mathrm{C}$ with a standard deviation of $0.15^{\circ} \mathrm{C}$ and maximum of $37.9^{\circ} \mathrm{C}$. The safety of the surrounding tissues must be maintained; thus, we compared the temperature rise between the cancer tissue and healthy tissue. Figure 9 shows the SAR average $10 \mathrm{~g}$ maps for the case of the $300 \mathrm{MHz}$ and $1.06 \mathrm{GHz}$, for the z-y and $x-y$ plane, top and bottom, respectively. From Figure 9 it can be seen that the SAR is larger in the location of the cancer-mimicking tissue. The maximum SAR value was 0.25 and $6.32 \mathrm{~W} / \mathrm{kg}$ for $300 \mathrm{MHz}$ and $1.06 \mathrm{GHz}$, respectively. 


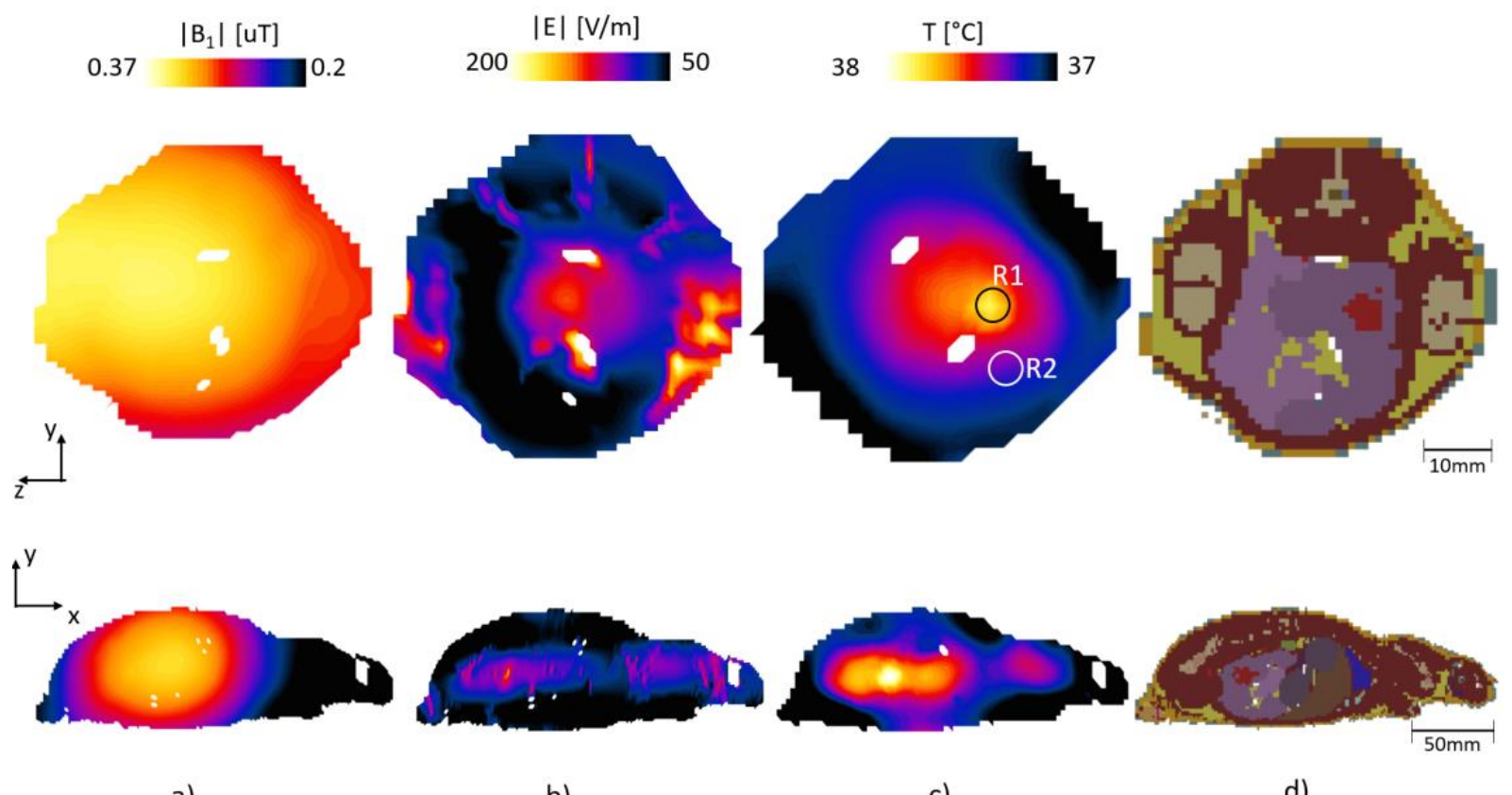

a)

b)

c)

d)

Figure 8. The computed (a) $\left|\mathrm{B}_{1}\right|$-field, (b) $|\mathrm{E}|$-field and (c) temperature map, for (d) voxel of rat model.

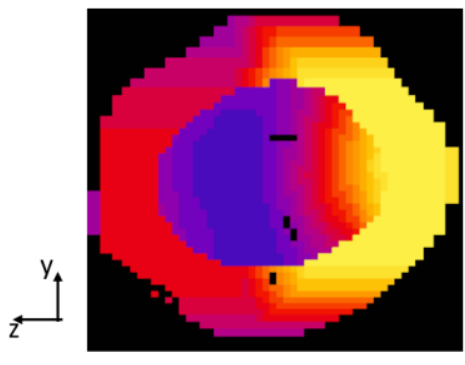

$\mathrm{SAR}_{10 \mathrm{~g}}[\mathrm{~W} / \mathrm{kg}]$

0 l 0.3

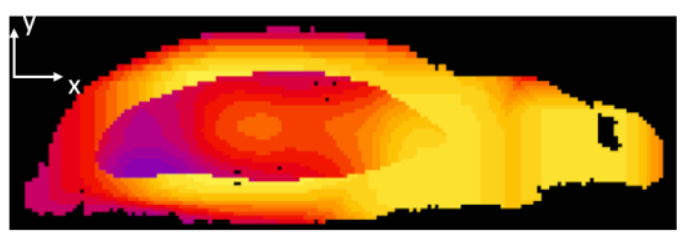

a)

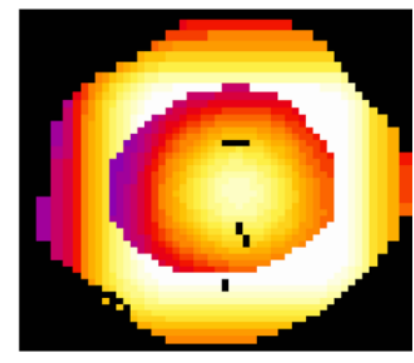

$\mathrm{SAR}_{10 \mathrm{~g}}[\mathrm{~W} / \mathrm{kg}]$

0

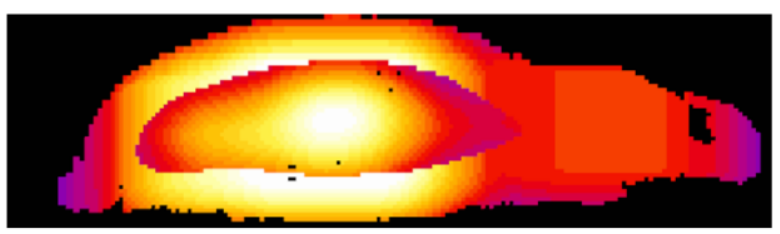

b)

Figure 9. The SAR average $10 \mathrm{~g}$ acquired at (a) $300 \mathrm{MHz}$ and (b) $1.06 \mathrm{GHz}$, for the z-y plane (top) and x-y (bottom).

Figure 10 compares the evolution of temperature in time for a point in a nearby healthy large intestine tissue (R2) and a point at the cancer tissue (R1), at the regions marked by a circle in the top of Figure $8 \mathrm{c}$. In addition, we included the volume histogram to show the evolution of the temperature in the cancer tissue Figure $10 \mathrm{~b}$ and also on the healthy tissue Figure 10c. The histogram shows the normalized volume at different temperature ranges. The bars in each bin represent the time in seconds. It can be seen that the temperature on the cancer tissue has move volume counts at the highest temperature range than in the healthy tissue. 
a)
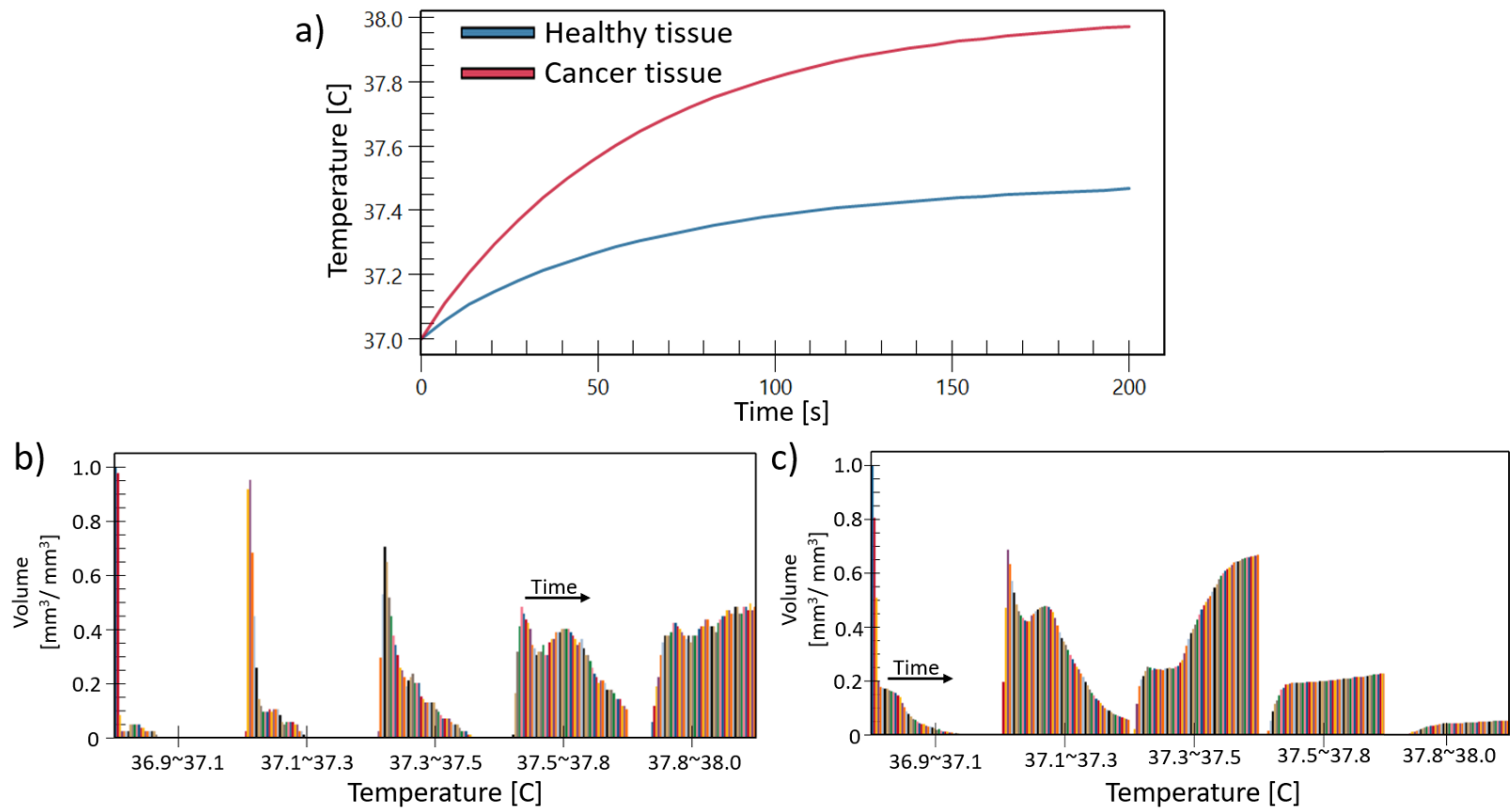

Figure 10. Temperature comparison as a function of time between healthy tissue (without RF heating focus) and cancer tissue (with RF heating focus) (a). The histogram of the temperature change on time in terms of normalized volume, for the case of (b) the cancer tissue, (c) the healthy tissue.

\section{Conclusions}

In this study, we presented a reduced-size patch antenna that can be used for MRI and RF heating. The size of the patch antennas was reduced by $61 \%$ width and $28 \%$ length using a meandering pattern in both the horizontal and vertical directions on the ground and patch plane. The designed patch antenna could produce a resonance mode at a frequency of $300 \mathrm{MHz}$ corresponding to 7T MRI system. At this frequency the $\left|\mathrm{B}_{1}\right|$-field is uniform for which it can be used for MR image. At a same time, the antenna had a resonance frequency at $1.06 \mathrm{GHz}$, at which the IE I field is used for RF heating procedures. We verified each resonant mode and determined the one corresponding to the dominant I E I-field such that it can be used for the application of RF heating. We also proposed a two-patch antenna configuration capable of producing a circularly polarized and uniform $\left|\mathrm{B}_{1}\right|$-field. However, this configuration can only be applied for small animal applications because the antennas are arranged along the $z$-axis and the position of the animal can be more easily controlled. The double patch antenna configuration also produced a strong and focused IEI-field, such that it could induce a temperature increase in a target cancer mimicking tissue. By reducing the size of the antenna, we have proposed a challenging antenna design; however, this can be achieved by using layers of copper tape attached to the dielectric material and then soldering each other. We can also create complex structures by using a 3D printer. A double tunned matching circuit can be developed for this application; however, it is outside of the scope of this work. For the case that the Hyperthermia procedure is applied in a separate time than MR imaging, an extra switch can be used to select corresponding the matching circuits. The proposed design of the patch antenna configuration can be used for combination of MRI acquisition for temperature measurement and hyperthermia with RF heating for treatments or preclinical studies with rats or mice. In the future, we will research on optimization of size adjustment for operating frequency, input power and exposure time for hyperthermia. 
Author Contributions: Conceptualization, D.H.; methodology, D.K.; validation, D.K. and D.H.; formal analysis, D.K.; writing - original draft preparation, K.-N.K.; writing-review and editing, K.-N.K.; funding acquisition, K.-N.K. All authors have read and agreed to the published version of the manuscript.

Funding: This work was supported by the Institute for Information and Communications Technology Promotion (IITP) grant funded by the Korean government (MSIP) (No. 2021-0-00490, Development of precision analysis and imaging technology for biological radio waves) and supported by Gachon University under the Gachon University research fund of 2018 (GCU-2018-0672).

Institutional Review Board Statement: Not applicable.

Informed Consent Statement: Not applicable.

Data Availability Statement: Not applicable.

Conflicts of Interest: The authors declare no conflict of interest.

\section{References}

1. Hoyer, C.; Gass, N.; Weber-Fahr, W.; Sartorius, A. Advantages and Challenges of Small Animal Magnetic Resonance Imaging as a Translational Tool. Neuropsychobiology 2014, 69, 187-201. [CrossRef]

2. Jonckers, E.; Shah, D.; Hamaide, J.; Verhoye, M.; Van der Linden, A. The Power of Using Functional fMRI on Small Rodents to Study Brain Pharmacology and Disease. Front. Pharmacol. 2015, 6, 231. [CrossRef] [PubMed]

3. Hjornevik, T.; Leergaard, T.B.; Darine, D.; Moldestad, O.; Dale, A.M.; Willoch, F.; Bjaalie, J.G. Three-Dimensional Atlas System for Mouse and Rat Brain Imaging Data. Front. Neuroinform. 2007, 1, 4. [CrossRef] [PubMed]

4. Dam, C.; Lindebjerg, J.; Jakobsen, A.; Jensen, L.H.; Rahr, H.; Rafaelsen, S.R. Local Staging of Sigmoid Colon Cancer Using MRI. Acta Radiol. Open 2017, 6, 2058460117720957. [CrossRef]

5. Harms, S.E. MRI in Breast Cancer Diagnosis and Treatment. Curr. Probl. Diagn. Radiol. 1996, 25, 193-215. [CrossRef]

6. Cheng, W.; Ping, Y.; Zhang, Y.; Chuang, K.H.; Liu, Y. Magnetic Resonance Imaging (MRI) Contrast Agents for Tumor Diagnosis. J. Healthc. Eng. 2013, 4, 23-45. [CrossRef] [PubMed]

7. Jhaveri, K.S.; Hosseini-Nik, H. MRI of Rectal Cancer: An Overview and Update on Recent Advances. Am. J. Roentgenol. 2015, 205, W42-W55. [CrossRef] [PubMed]

8. Wyatt, C.; Soher, B.; Maccarini, P.; Charles, H.C.; Stauffer, P.; MacFall, J. Hyperthermia MRI Temperature Measurement: Evaluation of Measurement Stabilisation Strategies for Extremity and Breast Tumours. Int. J. Hyperth. 2009, 25, 422-433. [CrossRef]

9. Stakhursky, V.L.; Arabe, O.; Cheng, K.S.; MacFall, J.; Maccarini, P.; Craciunescu, O.; Dewhirst, M.; Stauffer, P.; Das, S.K. Real-Time MRI-Guided Hyperthermia Treatment Using a Fast Adaptive Algorithm. Phys. Med. Biol. 2009, 54, 2131-2145. [CrossRef] [PubMed]

10. Curto, S.; Aklan, B.; Mulder, T.; Mils, O.; Schmidt, M.; Lamprecht, U.; Peller, M.; Wessalowski, R.; Lindner, L.H.; Fietkau, R.; et al. Quantitative, multi-institutional evaluation of MR thermometry accuracy for deep-pelvic MR-hyperthermia systems operating in multi-vendor MR-systems using a new anthropomorphic phantom. Cancers 2019, 11, 1709. [CrossRef]

11. Sumser, K.; Bellizzi, G.G.; van Rhoon, G.C.; Paulides, M.M. The potential of adjusting water bolus liquid properties for economic and precise MR thermometry guided radiofrequency hyperthermia. Sensors 2020, 20, 2946. [CrossRef]

12. Bing, C.; Nofiele, J.; Staruch, R.; Ladouceur-Wodzak, M.; Chatzinoff, Y.; Ranjan, A.; Chopra, R. Localised Hyperthermia in Rodent Models Using an MRI-Compatible High-Intensity Focused Ultrasound System. Int. J. Hyperth. 2015, 31, 813-822. [CrossRef] [PubMed]

13. Prasad, B.; Kim, S.; Cho, W.; Kim, J.K.; Kim, Y.A.; Kim, S.; Wu, H.G. Quantitative Estimation of the Equivalent Radiation Dose Escalation Using Radiofrequency Hyperthermia in Mouse Xenograft Models of Human Lung Cancer. Sci. Rep. $2019,9,3942$. [CrossRef] [PubMed]

14. Curto, S.; Faridi, P.; Shrestha, T.B.; Pyle, M.; Maurmann, L.; Troyer, D.; Bossmann, S.H.; Prakash, P. An integrated platform for small-animal hyperthermia investigations under ultra-high-field MRI guidance. Int. J. Hyperth. 2018, 34, 341-351. [CrossRef] [PubMed]

15. Adibzadeh, F.; Sumser, K.; Curto, S.; Yeo, D.T.B.; Shishegar, A.A.; Paulides, M.M. Systematic review of pre-clinical and clinical devices for magnetic resonance-guided radiofrequency hyperthermia. Int. J. Hyperth. 2020, 37, 15-27. [CrossRef]

16. Gasinska, A.; Hill, S. The Effect of Hyperthermia on the Mouse Testis. Neoplasma 1990, 37, 357-366. [PubMed]

17. Demura, K.; Morikawa, S.; Murakami, K.; Sato, K.; Shiomi, H.; Naka, S.; Kurumi, Y.; Inubushi, T.; Tani, T. An Easy-to-Use Microwave Hyperthermia System Combined with Spatially Resolved MR Temperature Maps: Phantom and Animal Studies. J. Surg. Res. 2006, 135, 179-186. [CrossRef]

18. Winter, L.; Oezerdem, C.; Hoffmann, W.; van de Lindt, T.; Periquito, J.; Ji, Y.; Ghadjar, P.; Budach, V.; Wust, P.; Niendorf, T. Thermal magnetic resonance: Physics considerations and electromagnetic field simulations up to $23.5 \mathrm{Tesla}$ (1 GHz). Radiat. Oncol. 2015, 10, 1-12. [CrossRef] [PubMed] 
19. Paulides, M.M.; Mestrom, R.M.C.; Salim, G.; Adela, B.B.; Numan, W.C.M.; Drizdal, T.; Yeo, D.T.B.; Smolders, A.B. A printed Yagi-Uda antenna for application in magnetic resonance thermometry guided microwave hyperthermia applicators. Phys. Med. Biol. 2017, 62, 1831-1847. [CrossRef] [PubMed]

20. Lodi, M.B.B.; Muntoni, G.; Ruggeri, A.; Fanti, A.; Montisci, G.; Mazzarella, G. Towards the Robust and Effective Design of Hyperthermic Devices: Case Study of Abdominal Rhabdomyosarcoma with 3D Perfusion. IEEE J. Electromagn. RF Microw. Med. Biol. 2020, 7249, 1. [CrossRef]

21. Winter, L.; Özerdem, C.; Hoffmann, W.; Santoro, D.; Müller, A.; Waiczies, H.; Seemann, R.; Graessl, A.; Wust, P.; Niendorf, T. Design and Evaluation of a Hybrid Radiofrequency Applicator for Magnetic Resonance Imaging and RF Induced Hyperthermia: Electromagnetic Field Simulations up to 14.0 Tesla and Proof-of-Concept at 7.0 Tesla. PLoS ONE 2013, 8, e61661. [CrossRef]

22. Kok, H.P.; Cressman, E.N.K.; Ceelen, W.; Brace, C.L.; Ivkov, R.; Grüll, H.; ter Haar, G.; Wust, P.; Crezee, J. Heating technology for malignant tumors: A review. Int. J. Hyperth. 2020, 37, 711-741. [CrossRef]

23. Paulides, M.M.; Bakker, J.F.; Chavannes, N.; Van Rhoon, G.C. A patch antenna design for application in a phased-array head and neck hyperthermia applicator. IEEE Trans. Biomed. Eng. 2007, 54, 2057-2063. [CrossRef] [PubMed]

24. Lim, S.; Choi, W.C.; Yoon, Y.J.; Kim, H. Modified rectangular patch antenna for improving heating uniformity in hyperthermia application. In Proceedings of the 2015 IEEE International Symposium on Antennas and Propagation \& USNC/URSI National Radio Science Meeting, Vancouver, BC, Canada, 19-24 July 2015; pp. 734-735. [CrossRef]

25. Elsaadi, M.; Aid, Y.; Abbas, M.; Embarek, A.; Salih, K. Hyperthermia for Breast Cancer Treatment Using Slotted Circular Patch Antenna. Circuits Syst. 2019, 10, 37-44. [CrossRef]

26. Khan, M.U.; Sharawi, M.S.; Mittra, R. Microstrip Patch Antenna Miniaturisation Techniques: A Review. IET Microw. Antennas Propag. 2015, 9, 913-922. [CrossRef]

27. Reed, S.; Desclos, L.; Terret, C.; Toutain, S. Patch Antenna Size Reduction by Means of Inductive Slots. Microw. Opt. Technol. Lett. 2001, 29, 79-81. [CrossRef]

28. Wong, H.; So, K.K.; Ng, K.B.; Luk, K.M.; Chan, C.H.; Xue, Q. Virtually Shorted Patch Antenna for Circular Polarization. Antennas Wirel. Propag. Lett. 2010, 9, 1213-1216. [CrossRef]

29. Desclos, L.; Mahe, Y.; Reed, S.; Poilasne, G.; Toutain, S. Patch Antenna Size Reduction by Combining Inductive Loading and Short-Points Technique. Microw. Opt. Technol. Lett. 2001, 30, 385-386. [CrossRef]

30. Alsath, M.G.N.; Kanagasabai, M.; Balasubramanian, B. Implementation of Slotted Meander-Line Resonators for Isolation Enhancement in Microstrip Patch Antenna Arrays. Antennas Wirel. Propag. Lett. 2012, 12, 15-18. [CrossRef]

31. Balanis, C.A. Antenna Theory Analysis and Design, 4th ed.; John Wiley \& Sons: Hoboken, NJ, USA, 2015.

32. Yoo, D.S. The dielectric properties of cancerous tissues in a nude mouse xenograft model. Bioelectromagnetics 2004, 25, 492-497. [CrossRef] [PubMed]

33. Wissler, E.H. 50 years of JAP: Pennes' 1948 paper revisited. J. Appl. Physiol. 1998, 85, 35-41. [CrossRef] [PubMed] 